and degree of defoliation. The only significant correlation in either year was between $\mathrm{DBH}$ and defoliation in the first year. In this instance, smaller diameter trees tended to have greater leaf loss, although the variability in DBH accounted for only about $5 \%$ of the variability in defoliation.

Efforts to compare acorn production with defoliation were hampered by the fact that overall acorn production was relatively low each year, with fewer than $30 \%$ of the trees having any visible acorns and no trees with a rating of 4 . However, there was a significant negative correlation ( $r=$ -.27 ) between these variables the first year, indicating that greater defoliation was associated with less acorn production. It is possible that this relationship was even stronger than indicated, since the data may have been biased by the fact that it was easier to observe acorns on defoliated trees since the foliage did not obscure them. There was not a significant correlation the second year.

\section{Trends}

There were significant correlations between defoliation, leaf-out date, and acorn production from year to year. The strongest relationship was for defoliation $(r=.87)$. The same trees that turned brown early in 1987 also did so in 1988 (table 1). This similarity may be due to physiological condition, microsite differences, genetic factors, or a combination.

There was also a consistent pattern of leafout date between years $(r=86)$. Trees that leafed out early the first year also did so the second. However, the average leaf-out date the second year was more than 2.5 weeks later than in the first year (fig. 2). Such a large difference in leaf-out date suggests that growth initiation and cessation in blue oaks are very sensitive to changes in environmental conditions.

The correlation of acorn production from year to year was weaker, but also highly significant $(r=.32)$ (table2). This supports the current view that certain trees are consistently better acorn producers in a stand,

TABLE 2. Cross-tabulation of number of trees in acorn rating groups, 1987 and 1988

\begin{tabular}{|c|c|c|c|c|}
\hline \multirow{2}{*}{$\begin{array}{l}1987 \text { acorn } \\
\text { rating }^{*}\end{array}$} & \multicolumn{3}{|c|}{1988 acorn rating } & \multirow{2}{*}{$\begin{array}{l}\text { Row } \\
\text { total }\end{array}$} \\
\hline & 1 & 2 & 3 & \\
\hline 1 & 129 & 33 & 1 & 163 \\
\hline 2 & 16 & 19 & 1 & 36 \\
\hline 3 & 0 & 1 & 0 & 1 \\
\hline $\begin{array}{l}\text { Column } \\
\text { total }\end{array}$ & 145 & 53 & 2 & 200 \\
\hline
\end{tabular}

- Acorn ratings on a scale of 1 to $4: 1=$ no visible acorns; 2 = acorns visible after very close examination; $3=$ acorns readily visible but not covering whole tree; 4 = acorns covering entire tree and limbs sagging from their weight (no trees were found with this rating). even though the actual magnitude can fluctuate greatly from year to year.

\section{Conclusions}

The results of this study suggest that summer defoliation of blue oaks from drought has little short-term impact on growth or survival. Even after two consecutive years of early leaf loss, not one of the 200 trees died. In early fall 1989, all trees were leafed out and appeared healthy with very little leaf loss. While size, dominance, or the percentage of dead branches had little relation to defoliation, trees that lost leaves early tended to leafout early the following spring.
California's blue oaks are apparently well adapted to withstand the adverse effects of periodic droughts. It is still too early to tell if drought has longer term consequences on the susceptibility of blue oaks to insects or diseases. Plot trees will be monitored for another 3 years to evaluate these relationships.

Douglas D. McCreary is Cooperative Extension Natural Resources Specialist, Integrated Hardwood Range Management Program, Department of Forestry and Resource Management, University of California, Berkeley. He is stationed at the UC Sierra Foothill Range Field Station, Browns Valley.

\title{
Selective oak removal does not harm water quality
}

\section{Michael J.Singer $\square$ Xiaohong Huang \\ Measurements before and after removal of oaks from $14 \%$ of a 250 - acre watershed indicated small but not statistically significant in- creases in the runoff/rainfall ratio and no change in nutrient or sedi- ment removal. Careful, selective oak removal appeared to have no harmful effect on water quality.}

For the past 10 years we have measured amounts of rainfall and runoff, and concentrations of suspended sediment, major cations and anions, $\mathrm{pH}$, and electrical conductivity in two watersheds at the Sierra Foothill Range Field Station. One has a perennial flowing stream, and the other, a stream that flows only in the winter. The watersheds are used for winter and spring grazing by beef cattle, and our purpose was to learn what effects selective oak removal for range improvement would have on watershed hydrology and water quality.

The uppermost portions of the watersheds were cleared of all trees between 1964 and 1966 to enhance range production. There was no further management of the watersheds until 1984 when additional, selective oak harvesting was initiated. Cutting and removal of the trees by a firewood contractor was done primarily during the dry summer months to minimize watershed disturbance. Nonmerchantable wood was piled and, after a few years, burned.
Water measurements began in 1980 before the selective removal of oak trees on the two watersheds. In this report, we discuss the effects on the 254.4-acre watershed with the perennial stream. Oaks were harvested on about $14 \%$ of the watershed beginning in July 1984 and ending in May 1986. Approximately 1,350 trees were removed on 37 acres.

\section{Results and discussion}

Water yield. An annual average 27.5 inches of rainfall was measured in the watershed during the last nine years. The average consists of two heavy rainfall years (1981-82 and 82-83) and several years that were well below the station average of 29 inches a year (table 1). Runoff from the watershed varied between 3 and 30 inches and averaged 15.8 inches. The annual ratio of runoff to rainfall varied between 0.143 and 0.775 (table 1 ). This ratio is useful when comparing runoff among years.

There was no statistically significant difference between the average precut and postcut rainfall, runoff, or runoff/rainfall ratio for the watershed. Rainfall (34 versus 22 inches) and runoff (18 versus 14 inches) were higher in the four precut years than in the postcut years, and the ratio was slightly higher postcut $(0.610)$ than precut $(0.489)$. We conclude that careful removal of this small area of oaks did not have a major impact on water yield. There is a possibility that there may be a long-term increase in water yield. If the first postcut year is not 


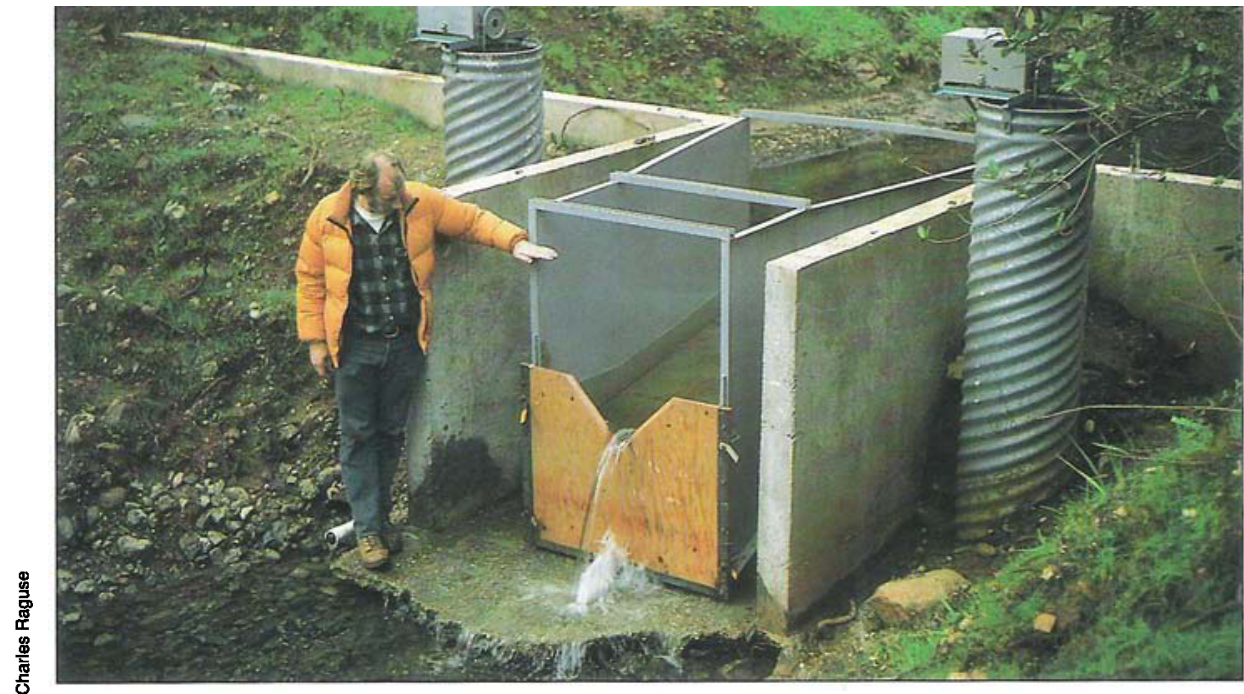

Researcher demonstrates the flume used to measure the amount of water flowing out of the field station's Schubert watershed.

included in the analysis, the average runoff/rainfall ratio is 0.665 but the difference is not statistically significant.

Comparisons between similar years show an apparent increase in runoff for the same rainfall. For example, in the 1980-81 precut year, 21 inches of precipitation generated 3 inches of runoff, while in the 1987-88 postcut year, 19 inches produced 11 inches of runoff (fig. 1). The higher runoff in the postcut year can be attributed to the distribution of rainfall, particularly the "priming" effect of the November and December storms followed by heavy rainfall in January. The early winter storms refilled the depleted soil moisture storage so that the January precipitation quickly saturated the soil and produced runoff. A similar pattern occurs when precut 1983-84 is compared with postcut 1988-89. In the precut year, 29 inches of precipitation caused 14 inches of runoff, while in the postcut year, 28 inches of precipitation caused 19 inches of runoff. The two precut years with highest rainfall (1981 through 1983) had a combined runoff/rainfall ratio of 0.66 compared with a ratio of 0.64 for the one postcut year (198586 ) when rainfall was above average. In the precut year 1980-81, runoff during every month of the rainy season was far less than rainfall (fig. 1). In the postcut year 1987-88, runoff exceeded rainfall during two months (fig. 1). This surprising result probably is due to the heavy rainfall in the three previous months. There are several springs in the watershed, and it is clear that a source of water in addition to the rain supplies the runoff. This does not appear to be due to the cutting.

Statistical tests (simple linear regressions of runoff as a function of rainfall) were run for precut and postcut years, but no significant correlation was found. (Although the $R^{2}$ was $>0.83$ for both, there were too few degrees of freedom to show significance.) From examination of the annual values and storm data, the oak harvest does not appear to have increased the runoff significantly during above-average rainfall years. Al- though not statistically significant, the overall average ratio of runoff/rainfall was higher from the watershed after than before cutting.

Sediment yield. The amount of sediment leaving the watershed is very small and was not adversely affected by oak harvesting. Fewer tons of sediment left the watershed after cutting than before, and tons per inch of runoff decreased about $50 \%$ after cutting. Total sediment depends on sediment concentration and runoff volume. Average suspended sediment concentration was weakly correlated to the average volume of runoff $(r=0.509)$. The suspended sediment concentration was not significantly different between precut and postcut years (table 1 ). The amounts of sediment leaving the watershed may be somewhat underestimated, because samples are taken at only one location and depth, and no bedload estimate is included.

Year-to-year comparisons between similar years are less clear for sediment production than for runoff. In the postcut year 1987-88, tripling the runoff tripled the total sediment load compared with the sediment The $35 \%$ greater runoff in $1988-89$ produced load for the precut year 1980-81 (table 1).
TABLE 1. Annual rainfall (RF), runoff (RO), runoff/ rainfall ratio (RO/RF), suspended sediment concentration (SUS), and total sediment load (SED) for Schubert watershed S2, Sierra Foothill Range Field Station, 1980-89

\begin{tabular}{lrrrrr}
\hline \hline Year & RF & RO & RO/RF & SUS & SED \\
\hline & in/yr & in/yr & & $m g / L$ & tons \\
$80-81$ & 21 & 3 & 0.143 & 14.6 & 1 \\
$81-82$ & 47 & 26 & 0.553 & 47.2 & 32 \\
$82-83$ & 40 & 31 & 0.775 & 32.4 & 25 \\
$83-84$ & 29 & 14 & 0.483 & 32.3 & 12 \\
& & & & & \\
Mean & 34 & 18 & 0.489 & 31.6 & 18 \\
& & & & & \\
$84-85$ & 18 & 7 & 0.389 & 13.6 & 2 \\
$85-86$ & 33 & 21 & 0.636 & 15.1 & 8 \\
$86-87$ & 13 & 10 & 0.769 & 40.2 & 10 \\
$87-88$ & 19 & 11 & 0.579 & 10.7 & 3 \\
$88-89$ & 28 & 19 & 0.679 & 21.2 & 10 \\
Mean & 22 & 14 & 0.610 & 20.0 & 6 \\
\hline
\end{tabular}

NOTE: Rainfall and runoff values are rounded to the nearest whole number.
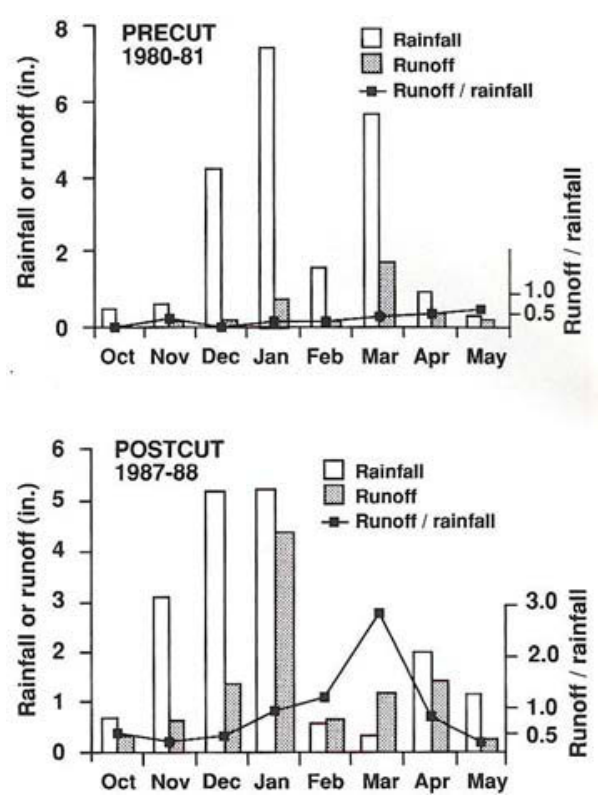

Fig. 1. Comparisons between years with a similar amount of rainfall in the watershed suggest that runoff increased somewhat after selective oak cutting.

nearly 2 tons less sediment than the precut 1983-84 year. Timing and intensity of precipitation events are evidently more important to the total sediment load than the removal of oaks on $14 \%$ of the watershed.

Nutrients in runoff. There were no significant differences between the precut and postcut sum of cations (calcium, magnesium, potassium, and sodium) leaving the watershed (table 2). The totals for both groups of years are small. The average annual sum of cations removed from the watershed during the precut years was 39.4 tons compared with 37.0 tons postcut. Additional cations were lost with the suspended sediment.

The chloride data are included because

TABLE 2. Annual NO -nitrogen, sum of cations (SC), chloride ( $\mathrm{Cl})$, and suspended sediment load (SED) for the Schubert watershed S2, 1980-89

\begin{tabular}{llllr}
\hline \hline YEAR & $\mathrm{NO}_{3}$ & $\mathrm{SC}$ & $\mathrm{CI}$ & SED \\
\hline $80-81$ & 0.048 & 8 & $\mathrm{ND}$ & 1 \\
$81-82$ & 0.355 & 68 & $\mathrm{ND}$ & 32 \\
$82-83$ & 0.431 & 47 & $\mathrm{ND}$ & 25 \\
$83-84$ & 0.005 & 35 & 0.9 & 12 \\
Mean & $0.210^{*}$ & 39 & $\mathrm{ND}$ & 18 \\
& & & & \\
$84-85$ & 0.579 & 21 & 1.2 & 2 \\
$85-86$ & 1.309 & 69 & 3.0 & 8 \\
$86-87$ & 0.411 & 26 & 0.7 & 10 \\
$87-88$ & 0.655 & 32 & 0.3 & 3 \\
$88-89$ & 2.124 & 36 & 0.6 & 10 \\
& & & & \\
Mean & $1.016^{*}$ & 37 & ND & 6 \\
\hline
\end{tabular}

$\mathrm{ND}=$ not determined.

*Significantly different at $90 \%$ by Fisher's Protected Least Significant Difference. 


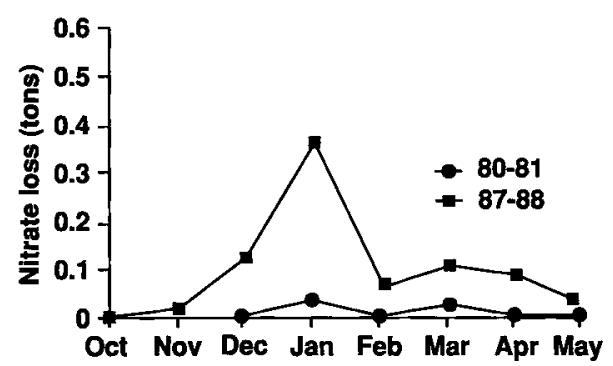

Fig. 2. Monthly nitrate loss during the rainy season was greater after oak harvest (1987-88) than before (1980-81).

chloride contamination of some wells in the valley has been a concern. Small amounts of chloride are leaving the watershed, presumably from weathering of chloride-containing rocks as soils form. We did not collect sufficient precut chloride analyses to make a precut versus postcut comparison.

Nitrate was significantly higher in postcut years (table 2). The precut average nitrate loss was 0.21 ton, and the postcut average was 1.016 tons. A comparison of monthly nitrate losses in the runoff shows that runoff and nutrient concentration were the same for precut and postcut years when there was no precipitation (June through September), but during months with precipitation, more nitrate was removed from the watershed after cutting than before (fig. 2). This appears to be related to nitrate concentration in the rainwater. Average nitrate concentra- tion in precut years from two collection points in the watershed was $0.006 \mathrm{mg} / \mathrm{L}$ and was $1.63 \mathrm{mg} / \mathrm{L}$ from the same two collection points in postcut years. Oak harvest could not affect the concentration of nitrate $\left(\mathrm{NO}_{3}\right)$ in rainfall. We must conclude that the increase in nitrogen in the stream was not due to the oak harvest.

\section{Conclusions}

Our results from 10 years of field monitoring of precipitation, runoff, and runoff water quality indicate that a small amount of carefully controlled oak removal has little effect on runoff volume and no effect on sediment or nutrients in the runoff. The runoff/rainfall ratio was numerically but not statistically higher for the five postcut years compared to the four precut years.

Nitrate nitrogen in runoff and rainfall was significantly higher in the postcut years. This may be a result of our collection system or analytical method. It cannot be said with any certainty that the increase in nitrogen in the stream water is due to the cutting. The total nutrients lost from the watershed are small and pose no water quality hazards.

Michael J. Singer is Professor of Soil Science, Xiaohong Huang is Graduate Research Assistant, and Charlette Epifanio is a former Graduate Research Assistant, Department of Land, Air and Water Resources, University of California, Davis.

\title{
Wildlife diversity of the central Sierra foothills
}

\author{
William M. Block a Michael L. Morrison
}

\section{A 3-year study of wildlife-habitat re- lationships in the oak woodlands of California's Sierra foothills found a wide range of species. This was di- rectly related to the diversity of habitats provided by oak wood- lands.}

California oak woodlands provide habitats for many wildlife species, including amphibians, reptiles, birds, and small mammals. Each species requires a unique set of resources to survive and reproduce, and the needs of wildlife change throughout the year. Animals found in oak woodlands only during the breeding season may use different resources than those found yearround or those occurring only during the
Our study, which included sampling by bird counts, live traps, pitfall traps, and timed searches, was conducted over most of the station's 5,700 acres. Only Forbes Hill (an area denuded of most woody vegetation) and the irrigated pastures were not sampled. Our sampling efforts incorporated much of the diversity of plant life and terrain typical of the central Sierra foothills. This diversity was the result of both natural events and human activities, such as grazing, fuelwood harvest, and fire suppression.

Except for two natural areas, one each in the Koch and the Schubert areas, most of the field station is grazed by cattle. Cattle grazing has modified the structure and composition of both woody and herbaceous vegetation. Natural areas have a denser shrub layer, less browsing on woody plants, and a taller herbaceous layer than the grazed areas.

\section{Bird counts}

We used a systematic-random sampling design to establish 100 sampling points. Points were spaced about 1,000 feet apart, a distance required to avoid recording the same bird at adjacent points. We recorded birds present at each point three times during each of the 1987 and 1988 breeding seasons (late March through May), and five times during the 1987-88 nonbreeding season (November through February).

The counts revealed 113 species, including 43 birds that were year-round residents, 11 species that resided only during winter but bred at other locations, 17 breeding species that wintered in other habitats, 21 migrant birds that used the area on the way to and from their breeding grounds, and 21 incidental species (table 1). More species were detected during breeding (82 in 1987 and 89 in 1988) than nonbreeding counts (60).

More species were recorded at Sierra Foothill Range Field Station than at two other areas-San Joaquin Experimental Range, Madera County, and Tejon Ranch, Kern County - where we also conducted bird counts. Most differences between $\mathrm{Si}$ erra Foothill and the other two areas were in the numbers of incidental species. Many of the incidental species at the field station were birds that used adjacent habitats such as Englebright Reservoir, Yuba River, and agricultural lands, and passed over or temporarily used the station's woodlands to or from their preferred habitats. Similar types of habitats were not adjacent to the other two study areas, possibly accounting for the differences in numbers of incidental species.

Discounting incidental species, 92 species used the field station for breeding, cover, or food. Species were similarly ranked by 